Volume: 11 Issue: 1 Year: 2014

\title{
Risk communication discourse: A content analysis of some Australian media coverage of cyclones in Queensland, Australia in 2011
}

\author{
Ahlam Mohammad Alharbi ${ }^{1}$
}

\begin{abstract}
As a cross-disciplinary field, the risk communication $(\mathrm{RC})$ discourse is complex. Thereof, media coverage of disasters as a fundamental resource of $\mathrm{RC}$ should be examined to guarantee successful delivery of risk information. Thus, this study investigated the content of risk information of cyclone-related news of the Brisbane Times and The Australian newspapers. It scrutinized the different types of risk-related messages by means of a quantitative content analysis based on the Extended Parallel Processing Model (EPPM) proposed by Witte (1980). The media coverage of the 2011 Queensland cyclones was examined with respect to the main question: what type of risk information the public was provided with? It was shown that the coverage of the Brisbane Times and The Australian might be enhanced by covering main components equally, focusing more on the component of efficacy, specifically 'the outcomes of preventive actions'.
\end{abstract}

Keywords: Risk-communication; Fear appeal; Extended Parallel Processing Model (EPPM); The 2011 Queensland's cyclones; and the Australian newspapers.

\section{Introduction}

Communication during time of risk is often termed risk communication (RC). As Rohrmann (2004) defines it, RC refers to "a social process" to inform the public about hazards, seek behavioral changes, and participate in making decisions concerning risk issues (p.1). RC can also be "any purposeful exchange of information about health or environmental risks between interested parties [such as governments, the media, companies, scientists, and the public regarding] (a) levels of health or environmental risks; (b) the significance or meaning of health or environmental risks; or (c) decisions, actions, or policies aimed at managing or controlling health or environmental risks" (Covello, Slovic, \& Von Winterfeldt, 1986, p.172). It has been noted that definitions of RC evaluate

\footnotetext{
1 Assistant Professor of linguistics, Taif University, Arts Faculty, Foreign Languages Department, Saudi Arabia,
} alharbi.ahlam@gmail.com 
Alharbi, A. M. (2014). Risk communication discourse: A content analysis of some Australian media coverage of cyclones in Queensland, Australia in 2011. International Journal of Human Sciences, 11(1), 1019-1036. doi: $10.14687 /$ ijhs.v11i1.2803

"the success of risk communication from the point of view of the senders of those messages, in terms of 'getting the message across'. The image is of experts enlightening or persuading an uninformed and passive public" ('US National Research', 1989, p.20). Additionally, reviewing a number of definitions of RC, Plough and Krimsky (1987) conclude that RC has five key components, i.e., intentionality, content, audience, source, and flow, which "[d]ifferent definitions of risk communication are narrow or broad depending on the latitude of interpretation of these elements" (p.6). On the other hand, RC research has discussed a number of problems of riskrelated information. Weterings and Eijndhoven (1989) point out four sources of such problems, i.e., the source of information, the information channel, problems concerning the receiver, and, most importantly, message problems (its content) either because of complexity or uncertainty, which are both inherited features of risk itself (p.473). Weterings and Eijndhoven (1989:481) further suggest two uncertainty dimensions of risk: (a) the uncertainty whether a specific incident may occur or not, and (b) the uncertainty of the predicted consequence. Yet, they note that the RC discourse should "(a) inform people about the risk assessment, (b) its results, and (c) to provide behavioral guidance” (p.378). Hence, any risk-related information provider has to aim at reducing the uncertainty of the targeted public, because the public usually feel incapable of "judging probabilities, making predictions, or attempting to cope with uncertainty. People deal with uncertainty by a variety of inconsistent and often illogical means" (Palenchar \& Heath, 2002, p.131). In consideration of the above discussion, content of risk-related information is of crucial importance to the RC discourse as a key component and, at the same time, a source of message problems. In essence, through the content much more is revealed related to reactions of the public, that is, how the public perceive and react based on their risk perceptions. It is worth mentioning that for this study and its goals, the content of the risk messages counts.

As noted earlier, one of the five key components of RC is the source of information. The media is one of the pivotal sources of information regarding natural hazards and extreme events. In so many words, the media influence how society, including the government, receives and responds to risks, hazards, and disasters (Pasquare` and Pozzetti, 2007, p.166). Pasquare`and Pozzetti (2007) summarize the aims of the media risk communication as simply to inform, notify, and provide the public with protective actions, plans, and resources to follow in order to survive (p.160). Similarly put, Renn (1992) points out that the media objectives are (1) to inform and educate the public to improve knowledge of risks, circularize information, and relieve and notify people about possible risks; and (2) to change or reinforce a behavior with respect to risks, either to promote a desired behavior or reduce risk-taking behaviors in emergencies (p.234). Although the role of media during 
Alharbi, A. M. (2014). Risk communication discourse: A content analysis of some Australian media coverage of cyclones in Queensland, Australia in 2011. International Journal of Human Sciences, 11(1), 1019-1036. doi: 10.14687/ijhs.v11i1.2803

disasters and hazards has become a matter of interest over many years (Ashlin \& Ladle, 2007, p.331), little has been done to examine the RC discourse delivered to the public by the media (Choi \& Lin, 2008, p.294). In order to contribute to the available research in RC literature, the present study extends the critical research on the discourse of crises by scrutinizing the coverage of two Australian newspapers, the Brisbane Times and The Australian, of the 2011 Queensland's cyclones, which turned out to be the worst in the nation's history. The significance of examining the discourse of the Australian newspapers stems from the fact that people in Australia, as Rohrmann (2004) indicates, "are exposed to multiple environmental hazards, like cyclones, fires, . . . and floods. Consequently, they face difficult tasks and crucial decisions” (p.2). He also asserts, "[a]uthorities must communicate the relevant information to residents and communities as a whole", as stated in the Australian/NZ Risk Management Standard (p.2). Thereof, it is crucial to examine the media coverage of disasters as a fundamental resource of RC to guarantee successful delivery of risk information. It is also worth mentioning that The Australian newspaper reported that Major General Slater has told media that "he had been pleasantly surprised by the coverage to date, which matched the 'great community spirit and great levels of co-operation' he had seen in Queensland" (Parnell, 2011, n.p.). The fact that the Australian media put great effort into covering natural disasters comprehensively is undeniable. Yet, it needs to be ascertained whether the riskrelated information these newspapers have provided has been sufficient, and also whether their risk-communication has been successful or not. To that end, this study employs the Extended Parallel Processing Model (EPPM) (Witte, 1980) (1) to probe critically the content of the selected risk information associated with different cyclone-related hazards; and (2) to assess the extent to which messages and information concerning the cyclones would prompt the public to not only understand the risks of the current cyclones, but also feel capable of responding to the present threat by seeking effective actions against this threat. The empirical implications of the present study include helping the media to construct a successful RC discourse more effectively. In so doing, this study addresses the following questions: (1) what type of risk information was the public provided with? (2) Did the risk-related information, as well as the risk-communication, increase the publics' awareness and understanding of the cyclones? (3) Did the newspapers mention the severity and threats of the cyclones, predicted damages, actions to take, and the expected outcomes of taking the recommended actions equally? and (4) Theoretically did the risk communication discourse lead to control threat or fear?

The paper first gives a brief account of RC and the EPPM, which is employed in the current study. In addition, a review of the data background, collection, and coding is presented. Then, this is 
Alharbi, A. M. (2014). Risk communication discourse: A content analysis of some Australian media coverage of cyclones in Queensland, Australia in 2011. International Journal of Human Sciences, 11(1), 1019-1036. doi: $10.14687 /$ ijhs.v11i1.2803

followed by a detailed analysis and discussion of the selected data.

\section{Risk Communication}

As a cross-disciplinary field, models in the RC and perception literature are various, for instance, the Theory of Reasoned Action (TRA), the Extended Parallel Processing Model (EPPM), and the Dialectical Discourse Model (DDM). These theories and models have provided valuable insight that extended our understanding of the RC discourse as well as the ways in which people may respond to the threat of any risk and the discourse itself. These theories overlap to some extent; however, they differ in their scopes. Zimmerman (2001) argues that the TRA and the EPPM "apply to risk impacting individual attitudes and behaviors toward risk—such as stopping smoking; weight control and exercise; safe sex-using condoms or abstinence; reducing or non-drinking” (p.2). On the other hand, the DDM "focuses more on societal issues, such as community reactions to proposed nuclear power plant sites, hazardous waste disposal facilities in a community, and logging in old growth forests" (p.2). In consideration of the questions the present study attempts to address, the TRA does not fit in the scope of the study. That is, as noted earlier the aim is to examine the content itself; however, the focus in the TRA is the attitude and behavior of the public, which is not the main focal point of this study. In addition, the third model, i.e., DDM, is not the most suitable one to employ due to its interests that are related to social matters.

Among these theories, the EPPM best describes the data and addresses the questions of the study. In more detail, the EPPM, proposed by Witte (1980), is a model that was developed "from the perspective of an individual receiving a persuasive message concerning [himself]" (Boyson et al., 2010, p.334). That is, the model primarily examines the content of the RC discourse with an aim to provide some insight on how the public may react to the message. In addition, Smith et al. (2008) indicate, "[t]he EPPM proposes that persuasive messages should present a potential threat that recipients will feel is personally relevant, and then show a relatively simple response that averts the threat" (p.203). Empirically, the EPPM has proven to be a valid framework on different healthrelated issues (Ngondo, 2008, p.2). Accordingly, the present paper examines the data under investigation employing the EPPM. The following section presents EPPM in more detail.

\subsection{Extended Parallel Processing Model (EPPM)}

The studies that examine the effectiveness of risk messages are formally known as fear appeal studies (Witte, 1996, p.318). Fear appeals at large are "persuasive messages designed to scare people by describing the terrible things that will happen to them if they do not do what the message recommends" (Witte, 1992, p.329). Lennon and Rentfro (2010) explain that research related to fear 
Alharbi, A. M. (2014). Risk communication discourse: A content analysis of some Australian media coverage of cyclones in Queensland, Australia in 2011. International Journal of Human Sciences, 11(1), 1019-1036. doi: $10.14687 /$ ijhs.v11i1.2803

appeal has scrutinized the structure of the risk-related messages (p.59). Additionally, examining the literature on fear appeals, Witte and Allen (2000) point out three pivotal variables of fear appeals, namely fear, perceived threat, and perceived efficacy (p.591). In theory, perceived threat has two sub-variables: perceived susceptibility to the threat (i.e., the degree to which one may feel at risk for the threat) and perceived severity of the threat (i.e., the expected damages from the threat). Although fear and threat are two different concepts, "they are intricately and reciprocally related" (p.592). That is, the higher the public perceive threat, the greater the fear they experience. On the other hand, perceived efficacy also has two sub-variables: (1) perceived self-efficacy (i.e., one's beliefs in terms of his ability to take the recommended protective actions); and (2) perceived response efficacy (i.e., one's beliefs in terms of the usefulness of the recommended protective actions). As Witte and Allen (2000) explain, theoretically fear appeal researchers usually assess the strength and effectiveness of a fear appeal through assessing at least two different messages, namely 'perceived threat' and 'perceived efficacy'. Typically, resultant outcomes of fear appeals can be classified into two categories: “(1) outcomes related to acceptance of the message's recommendations (i.e., attitudes, intentions, [sic] behaviors in line with the recommendations); and (2) outcomes related to rejection of the message (i.e., defensive avoidance, reactance, denial)" (p.592). With reference to the EPPM, in essence it is a result of the combination of various "old theories of fear appeals including Roger's (1975) protection motivation theory. . .Janis's (1967) explanations of when and why fear appeals fail, and Leventhal's (1970) parallel process model" (Ngondo, 2008, p.2). Being grounded in the fear appeal literature, the EPPM (see Fig.1, below) differentiates between two processes, namely danger control, a process that leads to message acceptance; and fear control, a process which leads to message rejection (Witte, 1992, p.337). As an overview, as Witte (1992) explains, the EPPM or a fear appeal initiates two appraisals: (1) the components of threat (i.e., severity and susceptibility), and (2) the components of efficacy (i.e., response efficacy and self-efficacy) (pp.337-338).

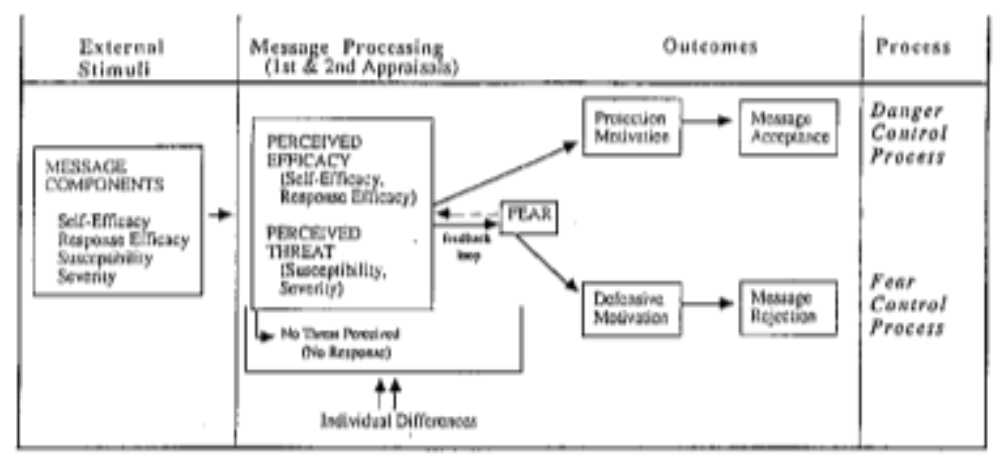

Fig.1 Extended Parallel Process Model (EPPM) (Witte, 1992, p.338) 
Alharbi, A. M. (2014). Risk communication discourse: A content analysis of some Australian media coverage of cyclones in Queensland, Australia in 2011. International Journal of Human Sciences, 11(1), 1019-1036. doi: 10.14687/ijhs.v11i1.2803

In other words, after receiving a threat message or a fear appeal, a person appraises it. In cases where threat is perceived as moderate or high, then fear is evoked and the receiver is ready to do the second appraisal, i.e., the efficacy of the suggested actions (Witte, 1992, p.338). In cases where a person perceives threat efficacy as high, then danger control processes are initiated. Witte (1992) explains:

When people fear an applicable and significant threat, and when they perceive a response that would feasibly and effectively avert the threat, they are motivated to control the danger (protection motivation) by thinking of strategies to avert the threat (adaptive outcomes). When danger control processes are dominating, individuals respond to the danger, not to their fear. (p.338)

Simply put, in this case the message is effective and successful in persuading the public and achieving its purpose. By way of contrast, when a person perceives threat as high and efficacy as low, then fear control processes are initiated. Witte (1992) adds:

The fear originally evoked by the personally relevant and significant threat becomes intensified when individuals believe they are unable to effectively deter the threat. Thus, they become motivated to cope with their fear (defensive motivation) by engaging in maladaptive responses (e.g., denial). When fear control processes are dominating, individuals respond to their fear, not to the danger. (p.338)

In this case, the message can be described as failing in achieving its purpose; on the contrary, the effect of the message, i.e., responding to fear, is unintended. On the other hand, if the appraisal of the threat is low because the threat is either insignificant or irrelevant, then the second appraisal simply will not take a place. In other words, the receiver will not respond to the threat message (p.338) as a result of its ineffectiveness. Taking into account the discussion above, the EPPM can indicate the (in)effectiveness of the fear appeals in persuading the public (Witte, 1992). Accordingly, through examining the content of the fear appeal, one can have some insight into how the public may act and react.

\section{Data and Methodology}

\subsection{Data Collection}

Using the news-network websites, a search was conducted using the following keywords: cyclones, Yasi, and Anthony, to collect the data. The corpus for this study consists of risk news stories during 
Alharbi, A. M. (2014). Risk communication discourse: A content analysis of some Australian media coverage of cyclones in Queensland, Australia in 2011. International Journal of Human Sciences, 11(1), 1019-1036. doi: $10.14687 /$ ijhs.v11i1.2803

Queensland's 2011 Cyclones published in the Brisbane Times and The Australian newspapers. The data is limited to a six-day time period (28 January, 2011 to 2 February, 2011 inclusive). The titles of these articles appear in the appendices (see, A \& B). It should be noted that the Brisbane Times and The Australian were among the newspapers that have reported this issue the most, as rated by Factiva. The following table presents a general summary of the data.

Table 1: Data Set

\begin{tabular}{lcc}
\hline Newspaper & No. of Articles & No. of Sentences \\
\hline Brisbane Times & 45 & 931 \\
\hline The Australian & 18 & 479 \\
\hline
\end{tabular}

\subsection{Data Contextualization}

Tropical cyclones are sometimes serious and life-threatening to Queensland communities and the Australian industries ('Australian Government', 2011, n.p.). The deadliest cyclone Australia in general and Queensland in particular experienced is widely held to have occurred on the $4^{\text {th }}$ of March, 1899. Some argue that the cyclone that occurred in January 1974 was the greatest. By and large, north Queensland is most affected by cyclones. These cyclones are usually formed between November and April with an average of 4.7 cyclones per year. In 2011 Queensland was hit by a severe tropical cyclone called Yasi, which was rated for some hours a marginal Category 5 (on a scale of one to five). It was reported that "the cyclone had a very destructive core with an estimated maximum wind gust of $285 \mathrm{~km} / \mathrm{h}$ ” ('Australian Government', 2011, n.p.). This cyclone crossed "approximately mid-way between the northern regional centers of Townsville and Cairns", which is an area of low population density ('Australian Government', 2011, n.p.), about midnight on Wednesday the $2^{\text {nd }}$ of February and moved inland on Thursday the third of February 2011 (Queensland Government, 2011, n.p.). Cyclone Yasi was preceded by cyclone Anthony a Category 2 cyclone. The destruction of these cyclones was devastating. It was reported that "Yasi is one of the most powerful cyclones to have affected Queensland since records commenced" (Australian Government', 2011, n.p.).

\subsection{Coding Categories}

In the present study, a quantitative content analysis is conducted to cover the different types of risk-related messages and examine its effectiveness in terms of the needs of the public. The analysis of the components concerning the risk related news, as well as the coding scheme, follow Witte's (EPPM) and the work of Choi and Lin (2008). In more detail, the content of messages is divided 
Alharbi, A. M. (2014). Risk communication discourse: A content analysis of some Australian media coverage of cyclones in Queensland, Australia in 2011. International Journal of Human Sciences, 11(1), 1019-1036. doi: $10.14687 /$ ijhs.v11i1.2803

into: (1) the components of threat i.e., severity of the cyclones and susceptibility or anticipated outcomes or damages; (2) the components of efficacy i.e., response efficacy (actions to take to prevent risks) and self-efficacy (expected outcomes of taking preventive actions). The coding units for the components of the EPPM might be a single word, a phrase, or a sentence. Based on these two methodologies, three steps are utilized in this study: (a) the number of the articles published in both newspapers is given; (b) the types of the articles published during the cyclone as well as their frequencies in both newspapers are provided; and (c) a quantitative content analysis is conducted to investigate the different components of the RC discourse in question. It should be mentioned that content analysis is the main research means utilized to examine the data. Content analysis is conducted because, according to White (2009), it helps "determine trends or patterns in the media (Weber, 1985), which add[s] a dimension to the qualitative data by allowing the researcher to quantify and identify issues through an objective and unbiased process" (p.182).

\section{Data Analysis}

As noted above, content analysis is conducted to examine the types of coverage as well as the components of RC. Table 2 below presents a rough quantitative overview of the data under investigation in terms of the types of coverage.

\section{Table 2: Type of Coverage}

\begin{tabular}{cccccccc}
\hline \multirow{2}{*}{ Newspaper } & \multicolumn{6}{c}{ Type of Coverage } & \\
\cline { 2 - 7 } & Hard News & \multicolumn{2}{c}{ Business } & \multicolumn{2}{c}{ Feature Stories } & \multirow{2}{*}{ Total } \\
\cline { 2 - 7 } & $\mathrm{N}$ & $\%$ & $\mathrm{~N}$ & $\%$ & $\mathrm{~N}$ & $\%$ & \\
\hline Brisbane Times & 37 & 82 & 6 & 13 & 2 & 4 & 45 \\
\hline The Australian & 13 & 72 & 4 & 22 & 1 & 6 & 18 \\
\hline
\end{tabular}

As seen from Table 2, the number of the articles published in the Brisbane Times is considerably higher than The Australian. That is, the Brisbane Times published double the number of articles that The Australian published during the environmental risk. In a six day period, the Brisbane Times published 45 articles on the cyclones, with an average of 7 to 8 articles per day. Conversely, The Australian published 18 articles in the same period, with an average of 3 articles per day. The types of articles published within the period under investigation are detailed in Table 2 as well. In regards to the types of articles, both newspapers produced three types of news stories, namely hard news stories, business oriented stories, and feature stories. It is notable that the Brisbane Times and The Australian primarily produced hard news stories, 37 articles (82\%) and 13 articles (72\%) respectively. 
Alharbi, A. M. (2014). Risk communication discourse: A content analysis of some Australian media coverage of cyclones in Queensland, Australia in 2011. International Journal of Human Sciences, 11(1), 1019-1036. doi: $10.14687 /$ ijhs.v11i1.2803

In addition, 6 articles (13\%) of the Brisbane Times were business oriented; whereas The Australian newspaper published 4 business oriented articles (i.e., 22\%). The last type, i.e., feature stories, made up the majority of the remaining articles, that is, 2 articles (4\%) of the Brisbane Times and 1 article $(6 \%)$ of The Australian. It is evident that the last category of news stories, namely feature stories, was kept to a minimum.

In the spirit of the EPPM, which is employed to scrutinize the effectiveness of the RC discourse on the 2011 cyclones, the following analysis of these types of news stories is principally divided into two main components of fear appeals: (1) the components of threat and (2) the components of efficacy. It is worth reminding the reader that each component has two sub-components that are also examined separately in each newspaper, i.e., 1) the severity of the cyclones, 2) discussed the predicted damages, 3) suggest efficacious preventive actions, and 4) adequately addressed expected outcomes of preventive actions. Table 3 below shows the different types and the frequency of riskrelated messages that were covered by the Brisbane Times and The Australian concerning the 2011 Queensland's cyclones.

Table 3: Components of Fear Appeal in the Data

\begin{tabular}{|c|c|c|c|c|c|c|c|c|c|c|}
\hline \multirow{4}{*}{ Newspaper } & \multicolumn{8}{|c|}{ Components of Fear Appeal } & & \\
\hline & \multicolumn{4}{|c|}{ Components of Threat } & \multicolumn{4}{|c|}{ Components of Efficacy } & & \\
\hline & \multicolumn{2}{|c|}{$\begin{array}{c}\text { Severity of } \\
\text { cyclones }\end{array}$} & \multicolumn{2}{|c|}{$\begin{array}{c}\text { Predicted } \\
\text { outcomes and } \\
\text { damages }\end{array}$} & \multicolumn{2}{|c|}{$\begin{array}{c}\text { Actions to } \\
\text { take }\end{array}$} & \multicolumn{2}{|c|}{$\begin{array}{c}\text { Expected } \\
\text { outcomes of } \\
\text { actions }\end{array}$} & \multicolumn{2}{|c|}{ Total } \\
\hline & $\mathrm{N}$ & $\%$ & $\mathrm{~N}$ & $\%$ & $\mathrm{~N}$ & $\%$ & $\mathrm{~N}$ & $\%$ & $\mathrm{~N}$ & $\%$ \\
\hline Brisbane Times & 141 & 15 & 58 & 6 & 69 & 7 & 6 & 1 & 274 & 30 \\
\hline The Australian & 47 & 10 & 38 & 8 & 19 & 4 & 0 & 0 & 104 & 22 \\
\hline \multirow[t]{3}{*}{ Total } & 188 & 13 & 96 & 7 & 88 & 6 & 6 & 1 & 378 & 27 \\
\hline & \multicolumn{4}{|c|}{ Components of Threat } & \multicolumn{4}{|c|}{ Components of Efficacy } & \multicolumn{2}{|c|}{ Total } \\
\hline & \multicolumn{2}{|c|}{$\mathrm{N}$} & \multicolumn{2}{|c|}{$\%$} & \multicolumn{2}{|c|}{$\mathrm{N}$} & \multicolumn{2}{|c|}{$\%$} & $\mathrm{~N}$ & $\%$ \\
\hline Brisbane Times & \multicolumn{2}{|c|}{199} & \multicolumn{2}{|c|}{21} & \multicolumn{2}{|c|}{75} & \multicolumn{2}{|c|}{8} & 274 & 30 \\
\hline The Australian & \multicolumn{2}{|c|}{85} & \multicolumn{2}{|c|}{18} & \multicolumn{2}{|c|}{19} & \multicolumn{2}{|c|}{4} & 104 & 22 \\
\hline Total & \multicolumn{2}{|c|}{284} & \multicolumn{2}{|c|}{20} & \multicolumn{2}{|c|}{94} & \multicolumn{2}{|c|}{7} & 378 & 27 \\
\hline
\end{tabular}

From the table, the components of fear appeals comprise only $30 \%$ of the Brisbane Times articles, i.e., 274 instances, and $22 \%$ of The Australian articles, i.e., 104 instances. It is also apparent that the 
Alharbi, A. M. (2014). Risk communication discourse: A content analysis of some Australian media coverage of cyclones in Queensland, Australia in 2011. International Journal of Human Sciences, 11(1), 1019-1036. doi: 10.14687/ijhs.v11i1.2803

most frequent type in both newspapers is 'the severity of the cyclones', which constitutes $15 \%$ (141 instances) of the Brisbane Times and 10\% (47 instances) of The Australian articles under investigation. That is, this component compromises almost half of the fear appeals in both newspapers. By way of contrast, the least frequent component is 'the expected outcomes of taking action', which is no more than 1\% (6 instances) in the Brisbane Times and $0 \%$ in The Australian. Regarding the other two components, the newspapers show different trends. In the Brisbane Times, 'the severity of the cyclones' is followed by 'the actions to take to prevent the risk' (69 instances, 7\%), then 'the predicted outcomes and damages' (58 instances, 6\%); whereas in The Australian, 'the severity of the cyclones' is followed by 'the predicted outcomes and damages" (38 instances, $8 \%$ ), then 'the actions to take to prevent the risk' (19 instances, 4\%). A statistical comparison between the two newspapers based on the frequency of each component was carried out employing an independent t-test. Regardless of the number of articles published by both newspapers, from Table 4 (see, appendix $\mathrm{C}$ ), it is apparent that there are no statistically significant differences in the percentages of the four components between the two newspapers. Accordingly, both newspapers are viewed equally. On the other hand, there are statistically significant differences between the percentage of the component of threat and that of the component of efficacy in both newspapers (see Table 5, appendix D). In so many words, in the Brisbane Times, the components of threat comprise $21 \%$ (199 instances), whereas the components of efficacy comprise only $8 \%$ of the data (75 instances). That is, the components of efficacy equal almost a third of the component of threat. On the other hand, in The Australian, the components of threat constitute $18 \%$ of the data under investigation, i.e., (85 instances), while the components of efficacy compromise no more than $4 \%$ of the whole data, i.e., (19 instances). To be more precise, the components of efficacy are less than a fourth of the components of threat.

As mentioned earlier, 'the severity of the cyclones' is the most prevalent type in the selected articles. Within this type of information, the strength of the cyclones $(88$ times, Brisbane Times and 25 times, The Australian) is the most frequently recurring information. Some other aspects of the cyclones such as their directions, movements, etc. (41 times, Brisbane Times and 22 times, The Australian) are the second most frequent type of information. Last but not least, miscellaneous information (20 times, Brisbane Times) is the least frequent type. On the other hand, 'the predicted outcomes and damages', which is the second component of threat, included information on different aspects such as 'closing facilities', 'increase of insurance rate', 'number of people/patients/animals evacuating', 'number of houses to be affected', 'electricity and mobile coverage', 'expected destruction' and 'emergency services availability'. 
Alharbi, A. M. (2014). Risk communication discourse: A content analysis of some Australian media coverage of cyclones in Queensland, Australia in 2011. International Journal of Human Sciences, 11(1), 1019-1036. doi: 10.14687/ijhs.v11i1.2803

Table 6: Predicted Outcomes \& Damages in the Data

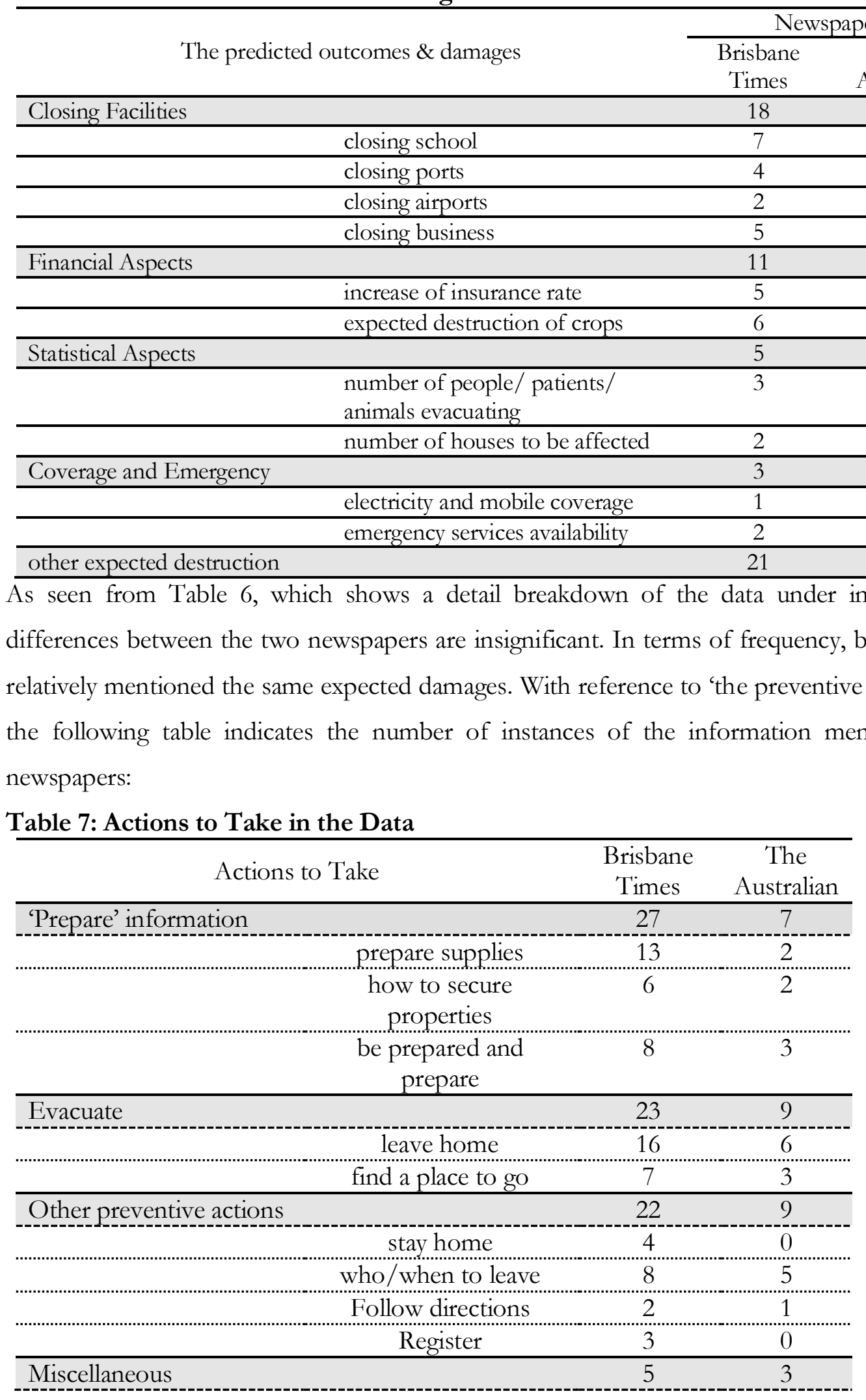

'The preventive actions to take', as a component of efficacy, included 'prepare' information as the most frequent action in the data (see, Table 7 above). This preventive action included 'prepare 
Alharbi, A. M. (2014). Risk communication discourse: A content analysis of some Australian media coverage of cyclones in Queensland, Australia in 2011. International Journal of Human Sciences, 11(1), 1019-1036. doi: $10.14687 /$ ijhs.v11i1.2803

supplies' and 'how to secure properties'. It was also frequently used by itself without other instructive actions 'do prepare, be prepared, and prepare'. The second frequent preventive action is 'evacuate' and it included 'leave home' and 'find a place to go'. Other preventive actions identified included 'stay home', 'who/when to leave', 'follow directions', 'register', and 'miscellaneous'. It is worth mentioning that the last component of fear appeal, namely, 'the outcomes of preventative actions', was employed only by the Brisbane Times six times (e.g., "if you. . ., you will be O.K."; "you will be at risk, if you do not. .."; "they should be O.K."; and "do. . .to ensure your safety").

\section{Discussion}

Kumagai, Edwards, and Carroll (2006) argue that natural disasters are among the most significant reasons of dislocation and disruption of people's lives (p.107). Accordingly, how a disaster is represented in print, broadcast, and other media sources should be investigated to promote the successful delivery of risk information. That is, it helps in promoting protective action decisionmaking through reducing uncertainty, as risk itself is a matter of uncertainty. As mentioned earlier, the content of risk messages or RC, which is examined in the present study, is one of problems that hinder the effectiveness of the delivery of risk information and a pivotal factor of RC. Interestingly, the quantitative content analysis in this study reveals pivotal findings concerning the coverage of the cyclones in the selected newspapers.

First of all, the number of the articles in both newspapers is crucial. Threatened by the worst cyclone in the nation's history, it would be highly recommended for The Australian, which published fewer than half of the number of the articles in the Brisbane Times, to publish more articles during disasters to keep its readers up-to-date. Needless to say, the number of the articles does not guarantee successful RC. One of the first observations that can be drawn from the components of the messages is that both newspapers, for the most part, treated the cyclones as hard news events, without detailed analysis of risk issues. This is evident in the types of news articles both newspapers published during the cyclones, where feature stories were rarely produced. Weick (1995) argues, "[t]hrough hearing the accounts of others who have experienced the event, individuals are able to make sense of a highly equivocal situation" (qtd. in Spence et al., 2007, p.543). Moreover, feature stories allow "individuals to observe the behavior of others in the given situation" (p.542). In terms of the efficiency of risk communication, this type of news articles might be more helpful and pivotal to the public, if both newspapers in question published more of this type during the cyclones. 
Alharbi, A. M. (2014). Risk communication discourse: A content analysis of some Australian media coverage of cyclones in Queensland, Australia in 2011. International Journal of Human Sciences, 11(1), 1019-1036. doi: $10.14687 /$ ijhs.v11i1.2803

As seen from Fig.2 below, and in light of the EPPM, the RC discourse in both newspapers, to some extent, might not be as successful and effective as it could have been. Remarkably, the total percentage of 'the expected damages', 'the preventive actions', and 'the outcomes of these actions' compromise no more than $14 \%$ of the whole data. By way of contrast, the articles under investigation provided the public with gross generalizations about the alleged severity of the cyclones compromising $13 \%$ of the whole data under inspection.

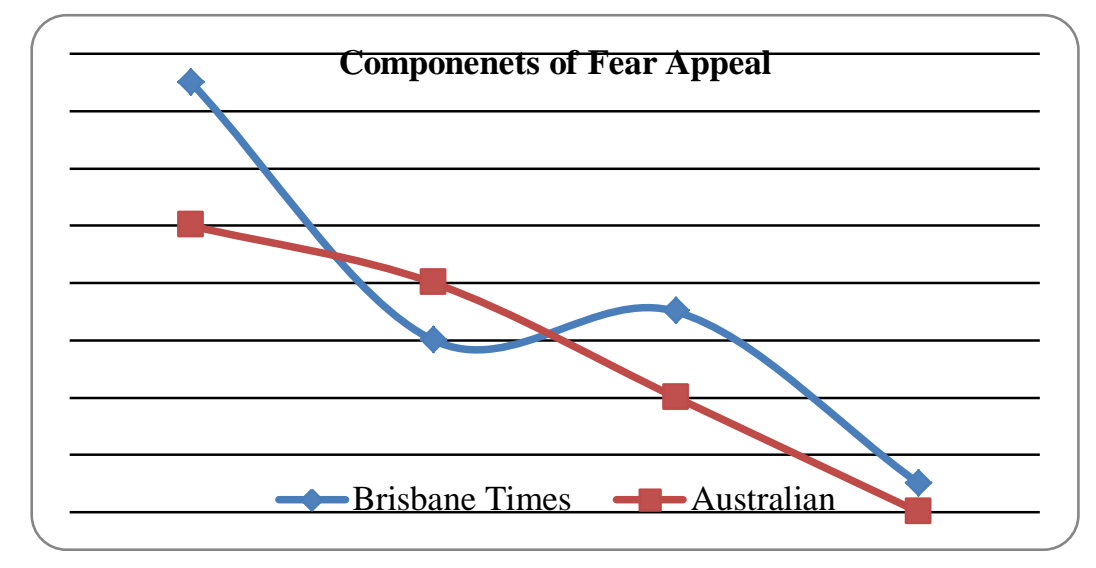

Fig.2 Components of Fear Appeal in both Newspapers

Furthermore, examining in depth the components of risk-related news reveals how the coverage was, to some extent, insufficient and deficient in its components. In more detail, with regards to the second component of 'the perceived threat', namely 'the predicted outcomes and damages', both newspapers provided the public with some unnecessary information that have nothing to do with individual protective actions, such as 'the increase of insurance rate' and 'the destruction of crops'; whereas pivotal information to the public, e.g., 'electricity and mobile coverage' and 'emergency services availability', was not equally mentioned. In terms of quantity, unnecessary business oriented information occurred more frequently than necessary information.

Undisputedly, the selected newspapers mentioned a number of important protective measures to ensure safety, reduce uncertainty, and, as Spence et al. (2007) note, to bring about "a sense of empowerment, allowing the individuals to feel as though they have some control in the situation" (p.543). Yet, from Fig.2, it is apparent that the component of efficacy was not of crucial importance to the newspapers, with 'the outcomes of preventive actions' making no more than $1 \%$ of the whole data, i.e., 6 instances which were employed only by the Brisbane Times. Choi and Lin (2008) explain, " $[\mathrm{w}]$ ithout knowing the predicted outcome of a preventive action, it is unlikely that people will follow the recommendations" (p.296). This certainly shows a lack of successful coverage, 
Alharbi, A. M. (2014). Risk communication discourse: A content analysis of some Australian media coverage of cyclones in Queensland, Australia in 2011. International Journal of Human Sciences, 11(1), 1019-1036. doi: 10.14687/ijhs.v11i1.2803

because it may not reduce uncertainty or assure the public that they are capable of protecting themselves.

As a result, and based on the EPPM and the statistical analysis (see Table 5, appendix D), the riskrelated messages in both newspapers theoretically might lead to fear control, which is a negative (unintended) result. As mentioned earlier, appraising the risk-related messages in both newspapers is done through appraising the two main components. The first component of the selected data, i.e., 'the components of threat', might result in high perceived threat. This appraisal is a result of the percentage and recurrence of 'the severity of the cyclones' in both newspapers. Receiving the threat as being high guarantees that fear was aroused leading to the second appraisal of the second component of fear appeal, i.e., the components of efficacy, to take a place. The evaluation of the components of efficacy in the selected articles is considerably low (see Table 5, appendix D), compared to the component of threat, with the Brisbane Times having 8\% (75 instances) and The Australian having 4\% (19 instances). The problem of the second component lies mainly in the second aspect of efficacy, namely 'the outcomes of preventive actions', which as noted earlier kept to a minimum (1\% in Brisbane Times and $0 \%$ in The Australian). It should be noted, however, that this study does not assume that fear control necessarily took place. At this point little can be concluded because such a finding requires a survey of journal readership. Yet, by providing the public with sufficient information and fulfilling the main two components of fear appeal, the media can satisfy the requirements of its role as an informational provider as a public service. As Witte (1992) argues, the result of these components that the media may achieve is to persuade the public to follow the instructions to save themselves.

Regardless of the insufficient appearance of the second component of fear appeal, the Brisbane Times covered all the sub-components of risk-related messages in their news stories. On the other hand, The Australian's discourse lacks one of the main components, namely the 'outcomes of the preventive actions'. Irrefutably, the risk-related information provided by both newspapers increased the publics' awareness and understanding of the cyclones. The great effort of the Australian newspapers specifically during crises is undeniable; yet, as this study has shown the Australian newspapers (in question) may enhance their discourse and coverage of environmental crises to meet the requirements of a successful RC discourse, because covering the news itself is not enough. Risk communication discourse is complex and should encompass successful coverage that takes into consideration the risk communication components equally. Articles that contain news and feature stories with a more detailed account of 'the actions the public may take' as well as 'the 
Alharbi, A. M. (2014). Risk communication discourse: A content analysis of some Australian media coverage of cyclones in Queensland, Australia in 2011. International Journal of Human Sciences, 11(1), 1019-1036. doi: $10.14687 /$ ijhs.v11i1.2803

outcomes of preventive actions' can persuade the public easily of the importance of following instructions, as well as, improve the success of the media in time of crises.

\section{Conclusion}

Media coverage, especially during time of environmental risks, is a double-edged sword. That is, it can either help people to make prudent decisions or make them feel helpless to react properly to any disaster. Similarly put, it may either alert them to a potential risk or make them deny it by helplessly trying to control their fear that might be aroused. As regards the present study, the purpose was to examine the content of the selected risk-related information concerning the 2011 cyclones in the Brisbane Times and The Australian newspapers to evaluate the fear appeal based on the EPPM. It has been noted that most of the reported news reviewed in this study was simply a factual account of the potential disaster. In addition, 'the severity of the cyclones' was one risk aspect that was greatly highlighted in both newspapers. On the other hand, the component of efficacy was rated as low, specifically 'the outcomes of the preventive actions'. However, as mentioned earlier, conclusions concerning the initiating of threat/fear control are limited due to the fact that the data is limited to the sample of the news articles published during the cyclone period. Yet, the findings in the current study allow the researcher to make the following recommendations:

1. The media during disasters might consider publishing more feature articles.

2. The media may construct fear appeals that compromise equally both components, i.e., components of threat and efficacy.

3. The media might focus more on 'the outcomes of the preventive actions'.

4. The media during disasters may focus primarily on the information that concerns the public.

To sum, through balanced and appropriate coverage of both threat and efficacy messages the media will be able to fulfill its pivotal role, specifically during crises. Hopefully, the findings of the present study provide insight that may help the media to construct fear appeal more effectively.

\section{Bibliography}

Ashlin, A. \& Ladle, R. J. (2007). Natural Disasters and newspapers: Post-tsunami environmental discourse. Environmental Hazards, 7, 330-341.

Choi, Y. \& Lin, Y. (2008). A content analysis of the newspaper coverage of the three major hurricanes in 2005. Public Relations Review, 34, 294-296.

Covello, V. T., von Winterfeldt, D. \& Slovic, P. (1986). Risk Communication: A Review of the Literature. Risk Abstracts, 3(4), 171-182. 
Alharbi, A. M. (2014). Risk communication discourse: A content analysis of some Australian media coverage of cyclones in Queensland, Australia in 2011. International Journal of Human Sciences, 11(1), 1019-1036. doi: 10.14687/ijhs.v11i1.2803

Pasquare`, F. \& Pozzetti, M. (2007). Geological hazards, disasters and the media: The Italian case study. Quaternary International, 173, 166-171.

Goei, R., Boyson, A., Lyon-Callo, S., Schott, C., Wasilevich, E., \& Cannarile, S. (2010). An examination of EPPM predictions when threat is perceived externally: An asthma intervention with school workers. Health Communication, 25(4), 333-344. doi: 10.1080/10410231003775164.

Gray, P. C. R., Stern, R. M., \& Biocca, M. (Eds.) (1998). Communicating about Risks to Environment and Health in Europe. Published on behalf of the WHO Regional Office for Europe in collaboration with the Centre for Environmental and Risk Management, University of East Anglia, UK. Kluwer Academic Publishers, Dordrecht.

Kinsella, W. J. (2007). Reconstructing Environmental Risk Communication: Toward a Critical, Constitutive Framework. Paper presented at the annual meeting of the International Communication Association, TBA, San Francisco. $\quad$ Retrieved February 21, 2011 from http://www.allacademic.com/meta/p171418 index.html

Kumagai, Y., Edwards, J., \& Carroll, M. S. (2006). Why are natural disasters not a "natural" for victims? Environmental Impact Assessment Review, 26:106-119.

McCarthy, M., Brennan, M., De Boer, M., \& Ritson, C. (2008). Media risk communication-what was said by whom and how was it interpreted. Journal of Risk Research, 11(3), 375- 394.

Ngondo, P. S. (2008, March). Merck's Gardasil vaccination campaign: A content analysis grounded in the extended parallel processing model. Paper presented at the Sooner Communication Conference, Norman, OK.

Parnell, S. (2011, January 31). Journos doing 'right thing' on flood coverage. The Australian Newspaper. Retrieved February 3, 2011 from http://www.theaustralian.com.au/business/ media/journosdoing-right-thing-on-flood-coverage/story-e6frg-996-1225997073812

Plough, A. \& Krimsky, S. (1987). The emergence of risk communication studies: Social and political context. Science, Technology, \& Human Values, 12(3 \& 4), 4-10.

Renn, O. (1992). Risk communication: Towards a rational discourse with the public. Journal of Hazardous Materials, 29, 465-519.

Renn, O. (2010). The Contribution of Different Types of Knowledge towards Understanding, Sharing and Communication Risk Concepts. Catalan Journal of Communication \& Cultural Studies, 2(2), 177-195.

Rohrmann, B. (2004). The Relevance of the Internet for Enhancing Disaster Preparedness of Residents. Proceedings, 11th Conference of the International Emergency Management Society (TIEMS), May 2004.

Smith, S. W., Rosenman, K. D., Kotowski, M. R., Glazer, E., McFeters, C., Keesecker, N. M., \& Law, A. (2008). Using the EPPM to Create and Evaluate the Effectiveness of Brochures to Increase the Use of Hearing Protection in Farmers and Landscape Workers. Journal of Applied Communication Research, 36(2), 200-218.

Spence, P. R., Lachlan, K. A., \& Griffin, D. R. (2007). Crisis Communication, Race, and Natural Disasters. Journal of Black Studies, 37, 539-554.

US National Research Council (1989). Improving Risk Communication, Report of the Committee on Risk Perception and Communication, NRC, Washington D.C., National Accademy Press.

White, C. (2009). Examining a crisis communication void: The role of context to mitigate issues. Journal of Communication Management, 13(2), 176-190.

Wilkinson, I. (2010). Grasping the Point of Unfathomable Complexity: The New Media Research and Risk Analysis. Journal of Risk Research, 13(1), 19-28.

Witte, K. (1992). Putting the Fear Back into Fear Appeals: The Extended Parallel Process Model. Communication Monographs, 59, 329-349.

Witte, K. (1996). Predicting Risk Behaviors: Development and Validation of a Diagnostic Scale. Journal of Health Communication, 1, 317-342.

Zimmerman, D. E. (2001). Risk Communication-Lessons from Communication Science. Society for Technical Communication. Retrieved 25 January, 2011 from: http://www.stc.org/confproceed/2001/PDFs/STC48-000064.PDF 
Alharbi, A. M. (2014). Risk communication discourse: A content analysis of some Australian media coverage of cyclones in Queensland, Australia in 2011. International Journal of Human Sciences, 11(1), 1019-1036. doi: $10.14687 /$ ijhs.v11i1.2803

\section{Appendices}

\section{Appendix A: Brisbane Times Articles}

1. Two cyclones to hit Qld next week

2. Qld warned of cyclone double whammy

3. Two cyclones threaten flood-ravaged Qld

4. Dual cyclone flooding could be worse than past month: Bligh

5. TC Anthony crosses Queensland coast, worse cyclone to come

6. First cyclone hits Queensland, but the big one is still building

7. Thursday's cyclone to be 'a state event'

8. Qld prepares for 'most savage' cyclone

9. Yasi's punch could dwarf Anthony's slap

10. Floods make heavy weather of insurance costs

11. Monster cyclone likely to hit Cairns

12. Batten down the hatches, warns Bligh

13. Inland communities at risk from Yasi: BoM

14. Sugar crop, tourism at risk from cyclone Yasi

15. Yasi will be worse than Larry: Bligh

16. Hotline set up for cyclone evacuees

17. Thousands face evacuation as severe cyclone bears down

18. Residents, tourists flee as cyclone nears Australia

19. Cats and dogs flown out of Yasi's path

20. Rio shuts Hail Creek coal mine

21. From go to whoa: How Yasi will affect north Queensland

22. Family battens down - again

23. Here it comes ... Cairns prepares for the worst

24. Yasi could become category five monster

25. Cyclone Yasi could spark heavy losses

26. Cyclone Yasi to strike with winds of $250 \mathrm{~km} / \mathrm{h}$

27. Another year, another cyclone for north Queensland sisters

28. Yasi looms large over tiny Tracy

29. 'Most life-threatening storm in generations'

30. Cyclone forces 300 schools to close

31. Cyclone Tracy-like scenes feared for Cairns

32. 'It will start being terrifying around lunchtime'

33. Mandatory mass evacuations at Innisfail

34. Don't let eye of storm foster false sense of security, warns Slater

35. Storm threatens 10,000 Townsville homes

36. Too late to leave: drivers told to stay put

37. Don't panic if roof lifts off: authorities

38. Canegrowers fear huge damage from Yasi

39. Bunkering down on an island paradise

40. Suncorp says claims cost to be capped $\$ 10 \mathrm{~m}$

41. Waves $12 \mathrm{~m}$ high to lash coast

42. West prepares to get wild

43. Homes to tumble 'like a house of cards'

44. Yasi to drop up to $300 \mathrm{~mm}$ of rain

45. Yasi starts to cross coast 
Alharbi, A. M. (2014). Risk communication discourse: A content analysis of some Australian media coverage of cyclones in Queensland, Australia in 2011. International Journal of Human Sciences, 11(1), 1019-1036. doi: $10.14687 /$ ijhs.v11i1.2803

\section{Appendix B: The Australian Articles}

1. Piece of paradise in 'controlled panic' EVACUATION - CYCLONE YASI -

2. A city flees as 'deadly' cyclone closes in

3. Doing it for ourselves

4. Cyclone threatens huge losses

5. Queensland's cycles of havoc

6. Tourists scramble for flights --- CYCLONE YASI

7. Building standards 'won't resist storms' --- CYCLONE YASI

8. Tempest another big blow for Cairns --- CYCLONE YASI

9. Cosgrove warns of more trauma --- CYCLONE YASI

10. North waits and watches for the monster to come --- CYCLONE YASI

11. Triple threat of wind, rain and storm surge --- FORCES OF NATURE

12. Fears full dam will cause new flooding

13. East coast battens down for intense cyclone

14. Battered state on red alert after cyclone hits

15. State told to brace for twin cyclones - WEATHER --- 2011 FLOOD DISASTER

16. Coalmines flooded by bureaucracy

17. Quick resumption after Pilbara storm

18. FISCAL STRATEGY --- 2011 FLOOD DISASTER State opts for cuts to meet repair bill

\section{Appendix C: Table 4: t-Test: Two-Sample Assuming Unequal Variances}

\begin{tabular}{lcc}
\hline \multicolumn{1}{c}{ Statistics } & Brisbane Times & The Australian \\
\hline Mean & 7.25 & 5.5 \\
\hline Variance & 33.58333333 & 19.66666667 \\
\hline Observations & 4 & 4 \\
\hline Hypothesized Mean Difference & 0 & \\
\hline $\mathrm{Df}$ & 6 & \\
\hline $\mathrm{t}$ Stat & 0.479632097 & \\
\hline $\mathrm{P}(\mathrm{T}<=\mathrm{t})$ one-tail & 0.32423578 & \\
\hline $\mathrm{t}$ Critical one-tail & 1.943180274 & \\
\hline $\mathrm{P}(\mathrm{T}<=\mathrm{t})$ two-tail & 0.64847156 & \\
\hline $\mathrm{t}$ Critical two-tail & 2.446911846 & \\
\hline
\end{tabular}

Appendix D: Table 5: t-Test: Two-Sample Assuming Unequal Variances

\begin{tabular}{lcc}
\hline \multicolumn{1}{c}{ Statistics } & Threat & Efficacy \\
\hline Mean & 19.5 & 6 \\
\hline Variance & 4.5 & 8 \\
\hline Observations & 2 & 2 \\
\hline Hypothesized Mean Difference & 0 & \\
\hline $\mathrm{Df}$ & 2 & \\
\hline $\mathrm{t}$ Stat & 5.4 & \\
\hline $\mathrm{P}(\mathrm{T}<=\mathrm{t})$ one-tail & 0.016312304 & \\
\hline $\mathrm{t}$ Critical one-tail & 2.91998558 & \\
\hline $\mathrm{P}(\mathrm{T}<=\mathrm{t})$ two-tail & 0.032624609 & \\
\hline $\mathrm{t}$ Critical two-tail & 4.30265273 & \\
\hline
\end{tabular}

